DOI: 10.12957/demetra.2017.28642

\title{
Educação Alimentar e Nutricional: a defesa de uma perspectiva contra-hegemônica e histórico-crítica para educação
}

\section{Food and Nutrition Education: The defense of a counter-hegemonic and historical-critical perspective for education}

Susana Moreira Padrão

Odaleia Barbosa Aguiar'

Gilcilene de Oliveira Damasceno Barã̃o

1 Universidade do Estado do Rio de Janeiro, Instituto de Nutriç̧ão, Departamento de Nutrição Aplicada. Rio de Janeiro-RJ,, Brasil.

${ }^{2}$ Universidade do Estado do Rio de Janeiro, Faculdade de Educação da Baixada Fluminense, Departamento de Gestão de Sistemas

Educacionais. Rio de Janeiro-RJ,, Brasil.

Correspondência / Correspondence

Susana Moreira Padrão

E-mail: susanampadrao@gmail.com

\section{Resumo}

Este ensaio se propõe a problematizar as estratégias da educação alimentar e nutricional, no âmbito dos programas de alimentação e nutrição, que, de maneira geral, têm apresentado pouca efetividade frente aos desafios do cenário atual, considerando o aumento contínuo do excesso de peso e da obesidade na população brasileira. Os programas nessa área, em geral, visam à disseminação de orientações e recomendações para o consumo de uma alimentação tida como adequada e saudável com vistas à promoção da saúde, tendo como modelo hegemônico a abordagem biomédica. Procurar-se-á apontar fundamentos teóricos e metodológicos da educação que tenham uma perspectiva histórico-crítica, voltada para a reflexão dos sujeitos sobre si e sobre as questões que influenciam suas práticas e hábitos alimentares, que buscam superar a perspectiva biologicista. $\mathrm{O}$ debate fundamenta-se na premissa de que o ato de se alimentar envolve dimensões socioculturais, ambientais, econômicas e afetivas que não devem ser ignoradas ou secundarizadas, pois são determinantes na formação de hábitos e escolhas alimentares, ou, por contradição, na falta de opções nessas escolhas. Compreendese que esses hábitos são forjados, em grande medida, pelas condições de vida e de trabalho dos sujeitos, com forte implicação na organização de seu cotidiano, em função das limitações que essas condições produzem. Portanto, intervir nessas escolhas exige cuidado, pois se lida com dimensões objetivas e subjetivas, em particular, aspectos culturais e sociais, além de exigir uma prática educativa fundamentada de forma crítica e com consistência 
teórica que possa contribuir com os propósitos estabelecidos nas intervenções da Educação Alimentar e Nutricional.

Palavras-chave: Educação. Educação em Saúde. Políticas Públicas. Hábitos Alimentares. Obesidade.

\section{Abstract}

This essay proposes to problematize the strategies of food and nutrition education in the context of food and nutrition programs, which, in general, have shown little effectiveness in the face of the challenges of the current scenario, considering the continuous increase of overweight and obesity in the Brazilian population. In general, the programs in this area, aim at the dissemination of guidelines, recommendations and information for the consumption of proper and healthy food, with a view to health promotion, having the biomedical approach as hegemonic model. It will seek to point out theoretical and methodological foundations of education that have a historical-critical perspective, focused on the subjects' reflection on themselves, their practices and eating habits, intending to overcome the biologicist perspective. The debate is based on the premise that the act of feeding involves socio-cultural, environmental, economic, emotional and affective dimensions that should not be ignored or subordinated, since they are determinant in the formation of eating habits and choices, or, by contradiction, in the lack of options in these choices. It is understood that these habits are forged, to a great extent, by the living and working conditions of the subjects, with a strong implication in the organization of their daily lives, in function of the limitations that these conditions produce. Therefore, intervening in these choices requires care, because it deals with objective and subjective dimensions, in particular, cultural and social aspects, in addition to requiring an educational practice that is critically grounded and with theoretical consistency, which can contribute to the purposes established in the interventions of Food and Nutrition Education.

Keywords: Education. Health Education. Public Policies. Food Habits. Obesity. 


\section{Introdução}

Recomendações alimentares, oficiais ou não, são normalmente disseminadas em programas de promoção da saúde e da alimentação adequada e saudável, por meio de práticas educativas, desenvolvidas em distintos ambientes e através de diversas estratégias. Instituições de ensino, de atenção básica à saúde e locais de trabalho têm sido espaços recorrentes utilizados para a realização de ações educativas, direcionadas a diversos grupos sociais, constituídos por sujeitos de diferentes segmentos e faixas etárias.

Práticas educativas são uma das formas mais usuais de intervenção, utilizadas desde as primeiras iniciativas no âmbito das políticas públicas sociais de alimentação e nutrição. Destaca-se nesse percurso o Serviço de Alimentação da Previdência Social (SAPS), criado na década de 1940, onde as ações de educação alimentar cumpriam papel estratégico e ideológico, nas políticas sociais do governo de Getúlio Vargas. Estrategicamente, as ações se propunham a divulgar informações sobre o valor nutritivo dos alimentos e regras para o consumo de uma alimentação racional e econômica, através de folhetos e cartazes, dirigidos aos trabalhadores, com prioridade aos de menor renda e seus familiares, procurando demonstrar preocupação e cuidado com a saúde da classe trabalhadora. Entretanto, na perspectiva ideológica a responsabilidade pelo consumo alimentar inadequado era atribuída ao próprio trabalhador quando, mesmo após ter acesso às informações e recomendações divulgadas, suas opções alimentares continuavam inalteradas, reduzindo, assim, um problema social a escolhas individuais. ${ }^{1}$

Atualmente, processos educativos na esfera das políticas sociais de alimentação e nutrição têm sido valorizados e bastante reproduzidos, apoiados no aumento da ocorrência das doenças crônicas não transmissíveis (DCNT) e, em especial, da obesidade, que vêm se ampliando rapidamente nas últimas décadas no país. A alimentação inadequada, somada à inatividade física, está entre os principais fatores de risco das DCNT, ${ }^{2}$ como também são objetos prioritários de intervenções pelo Estado. Nesse sentido, o consumo de uma alimentação saudável passa a ser preconizada como peça fundamental para promoção da saúde, afastando ou diminuindo adoecimentos, além de contribuir com uma série de outros benefícios que vão do bem-estar físico e mental à longevidade.

Este ensaio visa problematizar as estratégias da educação alimentar e nutricional, que, de maneira geral, mantêm hegemônica a abordagem biomédica, além de se propor a apontar fundamentos teóricos e metodológicos da educação histórico-crítica, que buscam superar as perspectivas idealistas e biologicista, que isolam as ações educativas dos contextos sócio-históricos. 
A evolução do estado nutricional da população: a materialidade de um grave problema de saúde pública

Para dar materialidade ao cenário que tem propiciado a ampliação das ações educativas no âmbito da saúde e da alimentação saudável, considera-se pertinente apresentar dados que explicam as crescentes preocupações e intervenções na área da alimentação e nutrição.

Segundo estimativas da Organização Mundial da Saúde (OMS), 70\% das causas de morte no mundo, em 2014, de um total de 38 milhões de óbitos, são atribuídas às DCNT. ${ }^{3}$ No Brasil, o aumento célere e sistemático na ocorrência das DCNT, entre elas as doenças cardiovasculares, cânceres, diabetes, enfermidades respiratórias crônicas e doenças neuropsiquiátricas, fez com que o percentual de causas de morte, imputado às doenças crônicas, triplicasse nos últimos 60 anos, atingindo 72,6\% dos óbitos, em 2014, em sua maioria antes dos 70 anos de idade. ${ }^{4}$

Pesquisa Nacional de Saúde/ Ciclos de Vida (PNS), de 2013, ${ }^{5}$ estimou em 56,9\% a população acima dos 18 anos com excesso de peso, percentual que representava mais da metade dessa população, atingindo cerca de 82 milhões de pessoas. Os dados indicam uma maior prevalência no sexo feminino $(58,2 \%)$ em relação ao masculino (55,6\%). Só a partir dos 65 anos de idade, esses percentuais começam a declinar, em ambos os sexos. Já a obesidade, alcançava 16,8\% dos homens e 24,4\% das mulheres, índices significativos que indicam um grave quadro de saúde pública no país. ${ }^{5}$

Em relação à evolução do estado nutricional, referente à população adulta com 20 anos ou mais de idade, os dados analisados confirmam o avanço dessas prevalências, evidenciando uma situação preocupante. As estimativas de crescimento do excesso de peso e da obesidade foram calculadas segundo dados da Pesquisa de Orçamentos Familiares - POF 2002-2003, ${ }^{6}$ POF 2008-20097 - e da PNS 2013, ${ }^{5}$ já referida, realizadas pelo Instituto Brasileiro de Geografia e Estatística (IBGE).

Os dados indicam um aumento contínuo do excesso de peso e da obesidade, ao longo desse período, ou seja, entre $2002-2003{ }^{6}$ e $2013,{ }^{5}$ na população de 20 anos ou mais de idade. Em relação ao sexo masculino, o excesso de peso passa de $42,4 \%$ para $57,3 \%$, e a obesidade, de $9,3 \%$ para $17,5 \%$. No caso das mulheres, esta evolução foi ainda mais acentuada, passando de 42,1\% para $59,8 \%$, ao passo que a obesidade cresce de $14,0 \%$ para $25,2 \% .{ }^{5}$ Esses percentuais mostram que as prevalências de obesidade praticamente dobraram nesse intervalo de dez anos.

Considerando que alimentação está entre os principais fatores de risco das DCNT, dados levantados pela Pesquisa de Orçamento Familiar-2008-2009, ${ }^{7}$ corroboram a evolução dessas prevalências. A pesquisa indicou o aumento sistemático do consumo de alimentos processados e ultraprocessados, com altos teores de gorduras, sódio e açúcar, baixo teor de nutrientes e alto valor energético. Além disso, apontou o baixo consumo de frutas, legumes e verduras, hábitos avaliados como inadequados para a promoção da saúde e que se coadunam com o estado nutricional 
apontado ${ }^{8,9} \mathrm{O}$ consumo médio de frutas e hortaliças se manteve estável, entretanto, estimado como metade do valor recomendado pelo Guia Alimentar para a População Brasileira. ${ }^{10}$

Da mesma forma, a Pesquisa Nacional de Saúde (PNS) de 2013, ${ }^{11}$ que apresenta informações sobre a percepção do estado de saúde, estilos de vida e doenças crônicas, também investigou o consumo de frutas e hortaliças pela população, avaliado como um marcador de alimentação adequada. $\mathrm{O}$ resultado mostrou que apenas 37,3\% das pessoas, de 18 anos ou mais de idade, consomem cinco porções diárias de frutas e hortaliças nas refeições e frutas ou sucos de frutas, entre as refeições, considerando a frequência semanal de consumo. Por seu turno, a Organização Mundial da Saúde (OMS) ${ }^{12}$ recomenda o consumo de pelo menos 400 gramas desses alimentos, equivalente a cinco porções diárias. De maneira geral, as mulheres $(39,4 \%)$ consomem maiores quantidades que os homens $(34,8 \%)$, sendo que a ingestão aumenta tanto com a idade como com o grau de escolaridade e renda da população. ${ }^{11}$

Os últimos dados levantados pelo sistema de Vigilância de Fatores de Risco e Proteção para Doenças Crônicas por Inquérito Telefônico (VIGITEL) indicam que, em 2015, passamos a ter mais da metade da população adulta, 53,9\%, com excesso de peso, alcançando o percentual de $57,6 \%$ entre os homens e 50,8\% entre as mulheres, ${ }^{13}$ ratificando, assim, os dados apurados pela PNS 2013. O mesmo levantamento assinala que a obesidade cresceu muito rapidamente, em ambos os sexos, atingindo 18,1\% dos homens e 19,7\% das mulheres. Esses percentuais apontam aumentos significativos na prevalência da obesidade na população adulta, considerando que ela passa de 11,8\%, em 2006, para 18,9\%, em 2015, confirmando a gravidade do problema de saúde pública no país. ${ }^{13}$

As pesquisas acima mencionadas, além de dados sobre consumo alimentar e perfil nutricional, apresentam informações complementares acerca do comportamento desses indicadores, levando em conta idade, sexo e escolaridade, entre outros. Em relação à escolaridade, as prevalências do excesso de peso e da obesidade diminuem, na população em geral e no sexo feminino, à medida que os anos de escolaridade aumentam, o que ocorre de forma mais acentuada quando ultrapassa 12 anos de estudos. ${ }^{13}$ A associação entre os efeitos ou decorrências da escolaridade e dos processos educativos em geral, realizados de maneira formal ou informal, nem sempre é direta ou deve ser apreendida na mesma perspectiva. Entretanto, ousa-se afirmar que é possível buscar transformar a realidade social, através de práticas e ações educativas, para além de contribuir, quase que exclusivamente, com a manutenção da produção e reprodução das relações sociais de exploração. Uma maior ou menor efetividade dependerá dos fundamentos em que se apoiem as práticas, e das articulações necessárias com as condições objetivas dos sujeitos participantes da ação educativa. Em particular, credita-se essa possibilidade às ações que incitam os sujeitos a refletir criticamente sobre a realidade onde estão inseridos. 
O cenário retratado pode justificar a disseminação ampla e abrangente de recomendações alimentares no país, veiculadas através de guias, boletins e cartilhas, entre outros veículos utilizados como instrumentos de apoio às ações de Educação Alimentar e Nutricional (EAN), no sistema de saúde e em outros setores, como o Guia Alimentar para a População Brasileira. ${ }^{14}$ Entretanto, mesmo não desconhecendo outras propostas e estratégias desenvolvidas para enfrentar o problema, e outros fatores de risco para além da alimentação, a situação de evolução do estado nutricional apresentada deixa incertezas quanto à efetividade dessas estratégias, entre elas as ações de educação alimentar e nutricional planejadas e executadas. Na realidade, os estados de adoecimento e de alimentação inadequada e insuficiente não devem ser apartados da totalidade social em que vivem os sujeitos. A problemática decorrente dessa associação e a prática educativa correspondente ou necessária devem ter como pressuposto ou referência fundamentos teóricos que possibilitem "a compreensão de certo objeto dado a sua raiz. Portanto, é natural olhar com desconfiança para a forma imediata de tudo aquilo que nos é apresentado". ${ }^{15}$

De um lado, constata-se que as ações educativas realizadas de forma isolada, descontínua e descontextualizada não são capazes de alterar o cenário onde elas são executadas nem enfrentar os desafios colocados. De outro, avalia-se que as opções teóricas e metodológicas de uma educação contra-hegemônica e crítica $^{a}$ podem facilitar a problematização dos elementos presentes no contexto social, apontados como indutores do quadro descrito, referentes à saúde e à alimentação. Por exemplo, o planejamento participativo e as circunstâncias da vida das pessoas, além do monitoramento e avaliações sistemáticas das ações e dos cenários, são etapas imprescindíveis de um processo educativo contra-hegemônico.

A partir desse contexto histórico, como pensar a educação e ações educativas? Que fundamentos teóricos e metodológicos podem apoiar a educação alimentar e nutricional (EAN), na perspectiva de contribuir com as transformações sociais possíveis e necessárias no cenário apresentado? Como fomentar, facilitar e ampliar o acesso a políticas sociais que busquem materializar direitos, como o direito humano à alimentação adequada e à saúde? Qual o papel que pode ser atribuído e assumido pela Educação Alimentar e Nutricional nesse cenário?

a Contra-hegemonia, como define Saviani no livro História das Ideias pedagógicas no Brasil, ${ }^{16}$ são teorias da educação que se "estruturam a partir e em função da prática educativa.[...] [com] objetivo de formular diretrizes que orientam a atividade educativa” (p. 399) e são contra a ordem vigente. Ademais, têm que ser críticas porque estas pressupõem um pensamento e uma teoria que questione a realidade para além das aparências e procure estabelecer articulações para apreender a essência das situações contraditórias na sociedade. 


\section{O contexto histórico e social de surgimento e consolidação da EAN}

A gênese da educação alimentar e nutricional tem circunstâncias materiais históricas no Brasil. Considera-se como marco o início do século XX, no bojo do surgimento da ciência da nutrição a partir do recrudescimento da má nutrição, da fome e da subalimentação, identificadas como problemas sociais no contexto da Primeira Grande Guerra. As dificuldades financeiras agravadas pela queda da exportação do café, principal produto exportado pelo país, fizeram, também, emergir um quadro grave de condições sanitárias inadequadas. Nesse contexto, surgiu um movimento conhecido como higienista, que fortaleceria o caráter biologicista da saúde e da nutrição, apoiado no avanço da fisiologia médica. ${ }^{17}$

Os fundamentos teórico-metodológicos das iniciativas atribuídas à educação nutricional estavam associados ao conhecimento que começa a ser sistematizado acerca do valor biológico dos alimentos e sua utilização pelo organismo. Pode-se considerar que a fome e a subnutrição tornaram-se o objeto da educação nutricional, avaliadas como um fenômeno social, mas que só poderia ser compreendido nos marcos da biossociologia, em função da forte interseção entre o social e o biológico. ${ }^{17}$ Entretanto, a proposta de intervenção, para o enfrentamento do problema social identificado, ficaria restrita à divulgação de informações sobre uma boa alimentação.

Posteriormente, na década de 1940, com a instituição dos programas de proteção ao trabalhador e à força de trabalho, no âmbito das políticas sociais de alimentação, como o mencionado SAPS, a educação alimentar e nutricional (EAN) se amplia e se materializa como um instrumento para orientação de escolhas alimentares pela população.

Santos $^{18}$ apresenta uma periodização para EAN identificando quatro fases distintas nesse percurso, que se diferenciam pela abordagem, pelos pressupostos e pelos objetivos traçados. De 1940 a 1960, os primeiros programas educativos, que integravam a incipiente política de alimentação, tinham como premissa a ignorância da população, considerada um entrave para superar as carências nutricionais. A população, culpabilizada e responsabilizada por seus problemas nutricionais, deveria ser educada para alterar hábitos alimentares, passando então a "comer melhor". As recomendações alimentares tinham como paradigma as necessidades estritamente biológicas, desconsiderando dimensões mais amplas na constituição dos hábitos e escolhas alimentares, inclusive a renda como principal determinante no segmento mais pauperizado da classe trabalhadora. Ensinar a comer corretamente era o principal propósito da EAN ensejada. ${ }^{19}$

Numa segunda fase, que compreende o período de 1970 a 1990, os indivíduos foram considerados vítimas da organização social capitalista, geradora de desigualdades sociais e dos problemas de carências nutricionais, determinados, em grande medida, pela insuficiência de renda. A partir deste diagnóstico, a EAN, que se propunha, até então, a ensinar como comer corretamente, foi alijada dos programas de alimentação e nutrição, dando lugar à suplementação 
alimentar. A EAN não seria capaz de alterar o cenário em que prevaleciam a desnutrição e as carências nutricionais, uma vez que a renda era o elemento determinante.

Na terceira fase identificada, dos anos 1990 até a década de 2000, a educação alimentar resgatada esteve vinculada aos processos que pretendiam oferecer subsídios à população, novamente por meio de informações sobre alimentação adequada, para que escolhas e um consumo alimentar corretos pudessem prevenir adoecimentos e problemas nutricionais. E finalmente, a partir dos anos 2000, com a legitimação e materialização de alguns direitos sociais, entre eles, o direito humano à alimentação adequada, os programas de EAN, alavancados igualmente pela disseminação das práticas de promoção da saúde, passaram a ter como objetivo fortalecer o poder de escolha e decisão dos indivíduos, ${ }^{18}$ o que significa robustecer a responsabilização individual, com todos os problemas que essa alternativa tende a provocar.

Vinculada aos contextos históricos e sociais e às políticas públicas mediadas e formuladas pelo estado, a EAN consolidou seu viés ideológico ao longo de seu percurso. Nesse sentido, buscou tornar universais e legítimos os diagnósticos, as proposições e recomendações alimentares emanadas do Estado, em grande medida no papel de representante da classe dominante, cumprindo, dessa forma, um dos pressupostos inerente às ações educativas, de reprodução e consolidação das ideias oriundas de uma classe social. Essa é a forma pela qual a educação, utilizada como instrumento ideológico da classe dominante, propaga ideários e opiniões, convertendo-as em universais, contribuindo com a produção e a reprodução do modo de produção capitalista e das relações sociais de exploração. ${ }^{20}$

Dessa forma, observa-se que as premissas das práticas educativas foram alteradas de acordo com o contexto histórico, os interesses em disputa, a correlação de forças e a necessidade de legitimar a proposta formulada pelos órgãos oficiais. Foi o que expressou o relato conciso da trajetória da EAN. ${ }^{18,21}$ Nos períodos demarcados, estavam presentes, ora com maior ou menor ênfase, os achados epidemiológicos e nutricionais que justificavam as ações oficiais propostas.

O caráter hegemônico, com vistas a atender demandas econômicas, é evidenciado, da mesma forma, nas campanhas direcionadas à introdução de soja na alimentação, realizadas na década de 1960. Nesse período, a educação nutricional foi utilizada com o propósito de impulsionar o consumo dos alimentos, entre eles a soja, enviados ao país a partir da instituição dos convênios entre o Ministério da Educação (MEC) e a United States Agency for International Development (USAID), visando aliviar os excedentes agrícolas americanos. ${ }^{22}$

Nas décadas seguintes, 1970 e 1980, o consumo da soja e seus derivados continuariam a ser motivados, mas agora em função da expansão do cultivo interno, através da divulgação de informativos e ações de educação. Além dos interesses econômicos, ficava evidente nas ações que direcionavam a EAN, com maior ênfase até os anos 1990, a supervalorização do aspecto nutricional 
dos alimentos, desconsiderando a relevância de outros elementos intrínsecos ao ato de se alimentar. ${ }^{23}$ Portanto, não se pode isolar a ação educativa na EAN do questionamento sobre as condições materiais de existência e o projeto de homem e sociedade que se quer manter ou transformar.

\section{Um discurso atualizado com a mesma abordagem biomédica}

Nas duas últimas décadas, vem sendo possível identificar mudanças no discurso acerca dos propósitos da educação alimentar e nutricional, no âmbito da formulação da política social em nível central. Esse discurso teria avançado na perspectiva da educação popular de vertente freiriana, ${ }^{\mathrm{b}}$ superando a racionalidade do modelo biomédico, ainda hegemônico na área da saúde e da nutrição. ${ }^{18}$

Elaborado pelo Ministério do Desenvolvimento Social e Combate à Fome, em 2012, o Marco de Referência de Educação Alimentar e Nutricional para as Políticas Públicas ${ }^{22}$ se apoia em uma concepção de educação popular e representa um arcabouço legal, através de diretrizes, leis e programas, para a agenda de EAN nas políticas públicas. Formulado em parceria com o Ministério da Saúde e o Ministério da Educação, o documento considera a EAN uma estratégia de prevenção e controle dos problemas alimentares e nutricionais contemporâneos, valoriza as diferentes expressões da cultura alimentar e fortalece hábitos regionais, além de avaliar avanços nos fundamentos teóricos e metodológicos de ações e programas.

O entendimento expresso pelos autores do documento considera que no setor saúde, as abordagens sobre a EAN se reposicionaram tanto no que diz respeito à concepção como em relação à valorização do tema no bojo das políticas públicas. Segundo seu paradigma atualizado, a EAN visa promover a prática autônoma e voluntária de hábitos alimentares saudáveis, devendo reconhecer as opções alimentares como resultado da disponibilidade e do acesso aos alimentos. A educação é defendida como uma ação crítica, contextualizada, com relações horizontais e valorização dos saberes e práticas populares, alinhando-se aos movimentos de democratização e de equidade. ${ }^{22}$

No entanto, apesar das mudanças observadas nas preleções e nas diretrizes das políticas e programas, as práticas educativas permaneceram, em particular, nas esferas municipais e estaduais, assentadas em um forte viés biologicista, sem grandes alterações do arcabouço teórico e metodológico e, consequentemente, sem problematizar a dificuldade de acesso à alimentação adequada. Nesse sentido, identifica-se um hiato entre os propósitos das políticas formuladas, em nível nacional,

b A vertente freiriana da educação, cunhada por Paulo Freire, ${ }^{24}$ na formulação da pedagogia do oprimido, procura identificar e valorizar os saberes dos sujeitos históricos, buscando contribuir com a transformação social e a democratização da sociedade, através do processo educativo. O foco da educação são os temas pautados em saberes de classe e forjados a partir da situação concreta e existencial. 
e as ações implementadas, bem como entre os discursos centrais e as práticas locais, onde ainda predominam, como mencionado, o enfoque biológico, em detrimento de abordagens que favoreçam uma reflexão dos sujeitos sobre as questões que influenciam suas práticas e hábitos alimentares. ${ }^{18}$

Mesmo no Marco de Referência de Educação Alimentar e Nutricional, ${ }^{23}$ em que se identificam avanços substantivos para superação dos fundamentos biologisistas da EAN, algumas questões devem ser problematizadas. Suas diretrizes e formulações teóricas e metodológicas, que incidem na prática educativa, não garantem uma formação histórico-crítica dos sujeitos, como seria necessário e esperado, nem contemplam a expectativa de apontar novas possibilidades e caminhos, no âmbito da educação alimentar e nutricional, no sentido de contribuir para superar cenários adversos.

No Guia Alimentar para a População Brasileira, lançado em 2006 pelo Ministério da Saúde, ${ }^{10}$ e revisado em 2014, ${ }^{14}$ percebe-se o mesmo hiato apontado por Santos, ${ }^{21}$ quando apresenta como propósito da promoção da alimentação saudável, "ampliar e fomentar a autonomia decisória dos indivíduos e grupos, por meio do acesso à informação para a escolha e adoção de práticas alimentares (e de vida) saudáveis". ${ }^{10}$ Entretanto, a estrutura normativa e prescritiva com a qual esse guia foi concebido, assim como a maior parte dos instrumentos utilizados para divulgar orientações alimentares, tende a priorizar ações na esfera da prevenção, e não da promoção. Pode-se, ainda, argumentar que regras, normas, sistemas de controle e mecanismos de coerção existentes nas sociedades, em todas as esferas e segmentos, tornam-se legítimos, pois são forjados ideologicamente, ou seja, apresentados como hegemônicos e universais.

Ações de prevenção, em linhas gerais, buscam intervir nos comportamentos alimentares na expectativa de diminuir os riscos para a saúde, além de valorizar o conhecimento científico em detrimento dos demais aspectos inerentes às culturas e hábitos alimentares. Com outra perspectiva, a promoção, segundo seu paradigma, procura potencializar a saúde, o bem-estar e a qualificação da existência. ${ }^{25}$ Ações de prevenção não conferem nem valorizam a autonomia dos indivíduos, pois isso implicaria em liberdade para gerir livremente sua vida, seu cotidiano e suas escolhas. Quando se advoga que o homem é livre por natureza e que exprime essa liberdade pela sua capacidade e possibilidade de escolha, sem que se avalie em que situações ou quais opções são colocadas para sua escolha, parece que essa decisão é também livre, ou seja, que todos podem escolher o que desejarem e em igualdade de condições. "Esta ideia de liberdade como igual direito à escolha é a ideia de liberdade da burguesia, e não a realidade histórico-social da liberdade."26

O processo que concebe o sujeito como apto para realizar escolhas racionais em liberdade está impregnado pela ideologia de um sistema cultural assentado na individualidade, na racionalidade e no liberalismo. ${ }^{27}$ Essa assertiva parte do pressuposto de que a capacidade dos indivíduos para exercerem essa liberdade de escolha depende dos conhecimentos adquiridos por cada um e das informações disponibilizadas, e não da capacidade coletiva de se perceber as limitações que as condições de existência materiais impõem nas suas possibilidades de escolha. 
Enfim, os textos utilizados nos processos educativos na área de nutrição e alimentação tendem a priorizar o enfoque preventivo e o conhecimento epidemiológico que costuma ser o principal argumento para justificar a intervenção. As ações voltadas para a divulgação de informações científicas buscam convencer os sujeitos a aderirem às recomendações em vez de buscarem potencializar a sua saúde, questões que estão no âmbito social e existencial, para além da dimensão técnica e normativa. ${ }^{18}$

\section{Os fundamentos teóricos e metodológicos para uma EAN histórica e crítica}

Avalia-se que a defesa de uma pedagogia histórico-críticac é aquela que se apresenta como a mais consistente, na proposição aqui colocada, de enfrentamento e superação dos desafios presentes no cenário referido, e numa sociedade desigual e com hegemonia do capital. A proposta de uma educação fundamentada na perspectiva histórica exige a compreensão das condições estruturais nas quais os sujeitos estão inseridos, e em sua dimensão crítica, estimula a indagação e o questionamento sobre sua existência diante das circunstâncias concretas. Dessa forma, a fundamentação na perspectiva histórica e crítica requer que as políticas públicas e sociais e suas ações educativas sejam capazes de intervenções que não considerem abstratamente a educação ou os sujeitos como capazes, individualmente, de transformar a realidade social sem que as estruturas sejam modificadas ou reformadas.

Observar as circunstâncias históricas e concebê-las criticamente significa objetivamente que, por exemplo, a fome tem materialidades diversas para sujeitos diferentes, pois como frisa Marx: "A fome é a fome, mas a fome que se satisfaz com carne cozida, comida com faca e garfo, não é a mesma fome que devora a carne crua com ajuda da mão, da unha, do dente." 28

Nesse sentido, os fundamentos associados ao senso crítico da educação, proposto pelo Marco de Referência de Educação Alimentar e Nutricional, ${ }^{23}$ não correspondem àqueles vinculados à pedagogia histórico-crítica, quando defende, por exemplo, a "educação enquanto processo permanente e gerador de autonomia e participação ativa e informada dos sujeitos" ou quando se afirma que

é importante que o indivíduo desenvolva senso crítico frente a diferentes situações e possa estabelecer estratégicas adequadas para lidar com ela [...]. Neste sentido, a EAN deve ampliar as suas abordagens para além da transmissão de conhecimento e gerar situações de reflexão sobre as situações cotidianas, e a busca de soluções práticas de alternativas. ${ }^{23}$

c Pedagogia concebida por Dermeval Saviani, no contexto das teorias contra-hegemônicas nos anos 1970, que é um marco importante no âmbito das ideias pedagógicas no Brasil. ${ }^{16-29}$ 
Nessas passagens defende-se uma educação para além da transmissão do conhecimento, e o que isto significa? Seria uma educação voltada para a prática e para a adaptação de como lidar com as situações adversas ou para contribuir com a transformação da realidade? Qual fundamentação, e que tipo de ação educativa se aponta como referência?

Recorrendo, ainda, a Saviani, ${ }^{29}$ são três os aspectos imprescindíveis que devem compor a ação educativa: teoria, prática e condições materiais. Assim, para o autor,

A ação educativa [...] se desenvolve a partir de condições materiais e em condições também materiais. Essas condições materiais configuram no âmbito da prática. Essa exerce-se no âmbito da materialidade e é um dos fundamentos da concepção pedagógica que está sendo objeto de análise, isto é, a pedagogia histórico-crítica, a qual, como se sabe, considera que a teoria tem o seu fundamento, o seu critério de verdade e a sua finalidade na prática. Isso significa que não podemos nos limitar a apenas pensar a prática a partir do desenvolvimento da teoria. Quando entendemos que a prática será tanto mais coerente e consistente, será tanto mais qualitativa, será tanto mais desenvolvida quanto mais consistente e desenvolvida for a teoria que a embasa. ${ }^{29}$

Ao tratar da materialidade da ação pedagógica, Saviani ${ }^{29}$ discorre sobre três desafios que a pedagogia histórico-crítica tem que enfrentar: a) a ausência de um sistema de educação; b) o surgimento de novos pressupostos teóricos que, geralmente, não têm correspondência com a organização objetiva para transformar a prática; c) a descontinuidade das políticas públicas. ${ }^{29}$

Estes desafios estão, igualmente, presentes na materialidade da ação educativa da EAN, como, por exemplo, na elaboração do Marco de Referência, ${ }^{23}$ quando expõe que o foco para sua formulação foi "a educação alimentar e nutricional para as políticas públicas". ${ }^{22}$ Haja vista que as políticas acontecem em várias frentes e redes de atuação, como na promoção da saúde, da alimentação e da segurança alimentar e nutricional, o que demanda organização e articulação de suas ações, que devem se desenvolver de forma permanente, transdisciplinar, intersetorial e multiprofissional.

Ao estudar o documento, destaca-se a ausência de um sistema nacional, ${ }^{\mathrm{d}}$ conforme proposição defendida por Saviani, ${ }^{29}$ que, na situação específica da EAN, poderia expressar uma coordenação nacional para enfrentar os problemas alimentares e nutricionais, que implicam na saúde individual e coletiva, superando assim a fragmentação observada nos diversos programas. Importa observar, que a ausência de uma coordenação atuante, apesar de toda a análise crítica e o avanço de algumas

d Para Saviani, ${ }^{30}$ "Já que no Brasil não existe sistema educacional, esta se apresenta, então, como uma tarefa para os educadores. Como realizar essa tarefa? O ponto de partida para o sistema são as estruturas. Uma vez que o homem mergulha nas estruturas, impõe-se o critério da coerência externa. É preciso tomar consciência das necessidades situacionais, aprofundar o conhecimento da situação de modo a se poder intervir nela, transformando-a no sentido da promoção do homem. E como não pode haver sistema sem atividade sistematizadora, por aí é que se pode começar. [...] Essa sistematização exige capacidade de reflexão e fundamentação teórica.” 
proposições, pode restringir, muitas vezes, a EAN, como estratégica para transformação das condições de saúde e nutrição, a slogans, sem permitir a consolidação de um campo específico de atuação. Essa assertiva se apoia no entendimento de que a EAN, enquanto objeto de intervenção, deve ser transversal, intersetorial e transdisciplinar, como proposto, no entanto, questiona-se de que forma será possível consolidar uma política pública estratégica, com um campo de ação tão amplo, complexo e disperso, sem uma instância de coordenação nacional.

Avalia-se que a ausência de um sistema nacional, ou o equivalente na EAN, pode ser uma das explicações centrais para o paradoxo relatado no documento: "ao mesmo tempo em que é apontada sua importância estratégica, o seu espaço de ação não é claramente definido. A educação alimentar e nutricional está em todos os lugares e ao mesmo tempo, não está em lugar nenhum.”22

A própria concepção de política pública no Marco de Referência não oferece suporte metodológico explícito, especialmente, quando na apresentação afirma-se que "este é um documento em contínua construção e deverá ter desdobramentos próprios conforme os setores que atuem em EAN forem incorporando os princípios aqui expostos nas suas práticas". ${ }^{23}$ Mais adiante, afirma-se que "o propósito deste documento em qualificar e referenciar as ações de EAN, além de promover um campo comum de reflexão e orientação prática [...] O fim intencionado com esta construção é fomentar e subsidiar novos desdobramentos dentro de cada setor que atue com EAN". ${ }^{23}$ Importa problematizar de que forma implantar, monitorar e avaliar uma política pública que se propõe a enfrentar os enormes desafios apresentados com um documento em construção? Entende-se que uma política pública, ou uma proposição para atender às políticas, como propõe o Marco de Referência, deve ser discutida, apresentada para consulta, se for o caso, e elaborada no que concerne à natureza, princípios, diretrizes e fundamentos, caso contrário, pode expressar inconsistência e ser de difícil apreensão e implementação. Não obstante, isto não significa que a política não possa ser revisada e atualizada periodicamente, quando o cenário se modificar ou a correlação de forças, presentes em sua formulação, tornar-se mais favorável ao atendimento das demandas sociais. Essa circunstância mostra-se mais inequívoca quando os fundamentos teóricos e metodológicos, que pretendem sustentar a política, estão definidos e incorporados às premissas da política.

As ações públicas propostas não são calcadas em uma definição explicita que aponte uma direção para a EAN, especialmente, sobre o por que, para quê, para quem e o como desenvolver as ações educativas. Essas questões exigem respostas sustentadas por uma opção política clara quanto ao papel econômico e ideológico que a educação deve assumir diante das políticas públicas, principalmente, considerando que o papel do Estado é atender, preferencialmente, aos interesses do capital.

Outro desafio da educação, pontuado por Saviani, ${ }^{29}$ guarda, também, relação com as ações de EAN, quando se argumenta que o avanço teórico nesta área não deve estar dissociado das mudanças objetivas da prática. Caso isso aconteça, corre-se o risco de se criar um fosso entre o 
proposto, apoiado na teoria, e as condições para sua realização prática. Qualquer ação no âmbito da educação alimentar e nutricional deve ter como fundamento teórico a inevitabilidade de conceber a prática às condições materiais. Essas ações não podem neutralizar ou apagar as circunstâncias das problemáticas alimentares e nutricionais a que os sujeitos estão submetidos, pois nem sempre no âmbito da EAN as circunstâncias socioeconômica e cultural dos sujeitos aguardam interlocução com a ação educativa. As políticas públicas de educação e de EAN não devem propor intervenções e desdobramentos apartados das circunstâncias e das alternativas concretas alcançadas pelos sujeitos para lidar com as situações decorrentes da evolução do estado nutricional da população cuja materialidade expressa um grave problema de saúde coletiva. Portanto, na perspectiva de uma educação histórica-crítica, a teoria e a prática devem manter uma relação orgânica e premente como um de seus fundamentos centrais.

Por fim, ao considerar alguns elementos dos fundamentos teóricos e metodológicos na EAN, impõe-se o terceiro desafio ressaltado por Saviani: ${ }^{29}$ a descontinuidades das políticas. No processo histórico de gênese e de consolidação da EAN, evidenciam-se essas descontinuidades, muitas vezes acentuando o caráter difuso do campo de atuação de suas ações e o seu viés ideológico, muitas vezes apoiado em questões econômicas, políticas e sociais, responsáveis, em grande medida, pelos problemas alimentares e nutricionais. Superar essas descontinuidades não depende apenas da definição de melhores fundamentos e/ou aportes teóricos, mas da organização do campo da EAN com autonomia diante das políticas de Estado, inclusive para incidir de forma crítica em sua formulação.

A EAN deve se apropriar de referências teóricas para realizar a crítica ao modelo hegemônico das políticas, que, muitas vezes, projetam programas efêmeros, com ações pontuais e descontextualizadas, com restrição de recursos financeiros e desvinculação de um sistema ou coordenação nacional. Ademais, essas referências devem propiciar a instrumentalização para compreender as circunstâncias capitalistas da sociedade brasileira e facilitar o diálogo com os sujeitos, respeitando suas culturas e saberes, ao mesmo tempo que possibilita a apreensão do conhecimento científico que é exigido na prática da EAN.

Considera-se que um dos fundamentos metodológico centrais para o planejamento e execução de práticas educativas é a organização do campo da ENA, bem como o reconhecimento dos participantes como sujeitos históricos, através da EAN. Importa ressaltar que esses sujeitos devem se organizar coletivamente e, ao ter contato com o conhecimento científico, questionar as circunstâncias de sua existência e reivindicar políticas sociais públicas contínuas que transformem a realidade. Devem se reconhecer como os principais contribuintes do fundo público, que sustentam as políticas públicas em geral, e as específicas no campo da EAN, que são um direito incontestável de todos, individual e coletivamente. 


\section{Considerações Finais}

O comportamento alimentar das populações é uma questão extremamente complexa, por ser a alimentação uma necessidade que deve ser satisfeita para garantir a vida e uma ação que se deve realizar todos os dias e durante toda a existência. ${ }^{31}$ Não é possível prescindir da alimentação, eliminá-la ou substituí-la, como ocorre com outros hábitos sociais, que podem ser suprimidos, caso os sujeitos decidam ou desejem.

As múltiplas dimensões, atreladas ao ato de se alimentar e aos hábitos alimentares, deixam o alimento e a alimentação submetidos a diferentes interesses políticos, econômicos e culturais, como aqueles associados à indústria alimentícia, ao agronegócio, à mídia e à publicidade, que tentam influenciar as escolhas e o consumo alimentar. A partir desse conjunto de elementos que compõe o comportamento alimentar, é possível inferir a complexidade e as dificuldades inerentes às iniciativas que buscam trabalhar com hábitos e opções alimentares, sem levar em conta os determinantes sociais da questão. Só encontraremos caminhos para identificar e enfrentar os determinantes dos problemas alimentares, que se agravam, a partir da realidade concreta, ou seja, uma sociedade de classes cujas diferenças e especificidades devem ser conhecidas e consideradas na formulação das ações de intervenção. Isto pressupõe que devemos partir do real e possível.

A questão alimentar, tanto em relação ao padrão de consumo como no que se refere à dificuldade de acesso aos alimentos, e suas consequências alimentar e nutricional, é uma questão social cuja intervenção deve ocorrer coordenadamente no plano macroestrutural, com medidas que articulem ações de diferentes esferas e instâncias de poder, e entre elas, as ações educativas. Considerando-se que indicadores de saúde e nutrição refletem desigualdades sociais e diferenças de renda, moradia, educação, acesso aos serviços públicos, gênero, e entre etnias, a melhora ao acesso à atenção básica à saúde e de renda da população, ocorrida nos últimos anos, ${ }^{32}$ poderia ter revertido a tendência observada de aumento acentuado das DCNT, relatado nas pesquisas apresentadas. No entanto, a evolução desses indicadores, que deveriam influenciar positivamente os dados relativos à saúde e à alimentação, não tem tido a repercussão esperada. Como exposto, a evolução do estado nutricional, referente à população adulta no país, confirma o avanço inconteste das prevalências de excesso de peso e obesidade, evidenciando uma situação preocupante e um grave problema de saúde pública.

A Política Nacional de Alimentação e Nutrição, atualizada em 2012, ${ }^{32}$ apresenta algumas contribuições para essa reflexão e o reposicionamento dos processos de educação associados à promoção da saúde e ao acesso à alimentação adequada. O texto reforça a necessidade de superação do modelo biomédico que se pauta pela doença, e não pela saúde, que ainda prevalece nas instâncias de atenção básica à saúde. Além de problematizar algumas questões, aponta a necessidade de se 
repensar processos, como: "as abordagens que se limitam à produção e à oferta de informações técnico-científicas; a frágil integração do conhecimento científico ao popular e a insuficiente apropriação das dimensões cultural e social como determinantes dos hábitos alimentares." ${ }^{3}$

Considera-se que programas e estratégias de educação alimentar e nutricional, transversais a diversas políticas no âmbito da política de segurança alimentar e nutricional e da alimentação e nutrição, podem dar contribuições importantes para enfrentar e amenizar o problema social apontado. Entretanto, acredita-se que essa assertiva só terá materialidade caso as práticas educativas planejadas e executadas sejam fundamentadas em uma perspectiva histórica e crítica, que busque criar condições para que os sujeitos possam problematizar, a partir de suas circunstâncias concretas, as condições sociais e, coletivamente, encontrar alternativas.

Por fim, observa-se que os processos educativos, largamente difundidos na área de alimentação e nutrição, estão fundamentados em teorias pedagógicas da educação formal, que tendem a reproduzir as relações de classe e a ideologia dominante e mascarar os determinantes dos problemas alimentares, priorizando a divulgação de requisitos para uma alimentação correta e saudável. A perspectiva de uma orientação crítica desses processos, que discuta e problematize as condições materiais de existência como um dos principais determinantes da questão alimentar, ainda não foi efetivamente incorporada por essas iniciativas, mas avalia-se que essa apropriação é urgente é necessária. Parece ser esse um caminho consequente e viável, a ser percorrido para que as possibilidades de transformação social se tornem mais próximas e concretas.

\section{Colaboradores}

Padrão SM participou da concepção, desenho do ensaio, redação, revisão e versão final do artigo. Aguiar OB participou da redação e revisão do artigo. Barão GOD participou da concepção, redação e revisão do artigo.

Conflito de interesses: Os autores declaram não haver conflito de interesses.

\section{Referências}

1. L'abbate S. As políticas de alimentação e nutrição no Brasil. I período de 1940-1964. Rev Nutrição 1988; 1(2):87-138.

2. World Health Organization. Noncommunicable diseases country profiles 2011. Geneva: WHO; 2011. 209 p.

3. World Health Organization. Global status report on noncommunicable diseases 2014. Geneva: WHO; 2014. 280 p. 
4. Malta DC, Oliveira TP, Santos MAS, Andrade SSCA, Silva MMA. Avanços do plano de ações estratégicas para o enfrentamento das doenças crônicas não transmissíveis no Brasil, 2011-2015. Epidemiol. Serv. Saúde 2016; 25(2):373-390.

5. Instituto Brasileiro de Geografia e Estatística. Pesquisa nacional de saúde: ciclos de vida. Brasil, grandes regiões e unidades da federação. Coordenação de Trabalho e Rendimento. Rio de Janeiro: IBGE; 2015.

6. Instituto Brasileiro de Geografia e Estatística. Pesquisa nacional de saúde. Pesquisa de Orçamentos Familiares 2002-2003: análise da disponibilidade domiciliar de alimentos e estado nutricional no Brasil. Rio de Janeiro: IBGE; 2004.

7. Instituto Brasileiro de Geografia e Estatística. Pesquisa nacional de saúde. Pesquisa de Orçamentos Familiares 2008-2009: antropometria e análise do estado nutricional de crianças, adolescentes e adultos no Brasil. Rio de Janeiro: IBGE; 2010.

8. Monteiro CA, Castro IRR. Porque é necessário regulamentar a publicidade de alimentos. Cienc Cult. 2009: 61(4):56-59.

9. Monteiro CA, Levy RB, Claro RM, Castro IRR, Cannon G. A new classification of foods based on extent and purpose of heir processing. Cad. Saúde Pública 2010; 26(11):2039-2049.

10. Brasil. Ministério da Saúde. Secretaria de Atenção à Saúde Guia alimentar da população brasileira: promovendo uma alimentação saudável. Brasília: Ministério da Saúde; 2006. Edição especial.

11. Instituto Brasileiro de Geografia e Estatística. Pesquisa nacional de saúde: percepção do estado de saúde, estilos de vida e doenças crônicas. Brasil, grandes regiões e unidades da federação. Coordenação de Trabalho e Rendimento. Rio de Janeiro: IBGE; 2014.

12. Word Health Organization. Diet, nutrition and the prevention chronic diseases. Geneva: WHO; 2003. WHO Technical Report Series, 916.

13. Brasil. Ministério da Saúde. Vigitel Brasil 2015: vigilância de fatores de risco e proteção para doenças crônicas por inquérito telefônico. Brasília: Ministério da Saúde, 2017. 169 p.

14. Brasil. Ministério da Saúde. Secretaria de Atenção à Saúde. Guia alimentar da população brasileira. 2 ed. Brasília: Ministério da Saúde; 2014. 152 p.

15. Filipe R. O céu (político) na terra (estudo à volta do para à questão judaíca do jovem Marx). Revista Vértice 2016 jul-ago-set; II(180):25-37.

16. Saviani D. História das ideias pedagógicas no Brasil. São Paulo: Autores Associados; 2007. 472 p.

17. Lima ES. Mal da fome e não da raça: gênese, constituição e ação política da educação nutricional. Brasil- 1934-1946. Rio de Janeiro: Fiocruz; 2000.

18. Santos LAS. O fazer educação alimentar e nutricional: algumas contribuições para reflexão. Ciênc Saúde Coletiva 2012; 17(2):207-216.

19. Brasil. Ministério da Saúde. Rede de Nutrição do Sistema Único de Saúde. Educação Alimentar e Nutricional. Brasília: Ministério da Saúde; 2010. Disponível em: http://ecos-redenutri.bvs.br>. [acesso em: 04 abr. 2017]. 
20. Saviani D. Escola e democracia: teorias da educação, curvatura da vara, onze teses sobre educação e política. Coleção polêmicas do nosso tempo. 22. ed. São Paulo: Cortez; 1989; 91p.

21. Santos LAS. Educação nutricional no contexto de promoção de práticas alimentares saudáveis. Rev. Nutrição 2005; 18 (5): 681-692.

22. Camossa ACA, Costa FNA, Oliveira PF, Figueiredo TP. Educação Nutricional: uma área em desenvolvimento. Alimentos e Nutrição. Araraquara 2005 out-dez; 16(4): 349-354.

23. Brasil. Ministério do Desenvolvimento Social e Combate à Fome. Marco de referência de educação alimentar e nutricional para as políticas públicas. Brasília: MDS; Secretaria Nacional de Segurança Alimentar e nutricional. Brasília, 2012. Disponível em: http://www.mds.gov.br/webarquivos/ publicacao/seguranca_alimentar/marco_EAN.pdf. [acesso em: 04 abr. 2017].

24. Freire P. Pedagogia do oprimido. 18. ed. Rio de Janeiro: Paz e Terra; 1988; 163p.

25. Czeresnia D, Freias C.M. Promoção de saúde: conceitos, reflexões e tendências. 2.ed.rev.e amp. Rio de Janeiro: Fiocruz; 2009; 229p.

26. Chauí M. O que é ideologia. 12. ed. São Paulo: Brasiliense; 1983; 125p.

27. Silva LF. Saber prático de saúde: as lógicas do saudável no quotidiano. Porto: Afrontamento; 2008; 203p.

28. Chagas EF. O pensamento de Marx sobre subjetividade. Revista Dialectus 2013 jan/jun; 2; Disponível em: file://C:/Users/Gilcilene/Downloads/72-269-2-PB\%20(3).pdf.

29. Saviani D. Pedagogia Histórico-Crítica. 8.ed. São Paulo: Autores Associados; 2003; 122p

30. Saviani D. Educação Brasileira: estrutura e sistemas. São Paulo: Autores Associados; 2000; 161p.

31. Mintz SW. Comida e antropologia. RBCS 2001; 16(47): p.32-41.

32. Barreto ML. Esboço para um cenário das condições de saúde da população brasileira 2022/2030. IN: Fundação Oswaldo Cruz. A saúde no Brasil em 2030 - prospecção estratégica do sistema de saúde brasileiro: população e perfil sanitário [online]. Rio de Janeiro: Fiocruz/IPEA/Ministério da Saúde 2013, v.2 p.97-120.

33. Brasil Ministério da Saúde. Política Nacional de Alimentação e Nutrição. Brasília; 2012. Disponível em: http://bvsms.saude.gov.br/bvs/publicacoes/politica_nacional_alimentacao_nutricao.pdf. [acesso em: 27 mar. 2017].

Recebido: 09/05/2017

Revisado: 17/07/2017

Aceito: 20/07/2017 